\title{
Pragmatic norms in science: making them explicit
}

\author{
María Caamaño Alegre
}

Received: 12 March 2010 / Accepted: 18 June 2012 / Published online: 3 July 2012

(C) Springer Science+Business Media B.V. 2012

\begin{abstract}
The present work constitutes an attempt to make explicit those pragmatic norms successfully operating in empirical science. I will first comment on the initial presuppositions of the discussion, in particular, on those concerning the instrumental character of scientific practice and the nature of scientific goals. Then I will depict the moderately naturalistic frame in which, from this approach, the pragmatic norms make sense. Third, I will focus on the specificity of the pragmatic norms, making special emphasis on what I regard as a key idea underlying them, namely, the view, vigorously advocated by classical pragmatists like C. S. Peirce and G. Vailati, that the best test for objectivity is the test of action. Finally, I am going to put forward a tentative list of pragmatic norms that can be abstracted from a careful observation and analysis of scientific practice as provided by current philosophers of experimentation (A. Franklin and F. Steinle among others). The norms will be divided into four classes corresponding to four aspects of science in which they rule, that is, self-correction, prediction, explanation and both experimentation and computation. In the following account, the formulation of those pragmatic norms successfully governing science will be understood as a contribution that scientifically-oriented pragmatism can make to the normative naturalistic project in epistemology.
\end{abstract}

The resemblance between this title and that of Robert Brandom's influential work, Making It Explicit (1994), is not casual. There he urged philosophers to make explicit those norms governing the use of words like 'truth' or 'reality' in actual linguistic practice, as the only way to provide an adequate characterization of the corresponding notions. The same need of explicitness is here vindicated with respect to norms guiding or aiming to guide scientific research, since no plausible understanding of such research seems possible if we ignore them..

M. Caamaño Alegre $(\varangle)$

Departamento de Filosofia, Facultad de Filosofia y Letras, University of Valladolid, Plaza del Campus s/n, 47005 Valladolid, Spain

e-mail: mariac@fyl.uva.es 
Keywords Pragmatic norms - Epistemic ends - Experimental predictions . Epistemological naturalism · C. S. Peirce · G. Vailati · W. V. O. Quine

\section{Science and the normative realm}

Unlike playing tennis or having popcorn, scientific practice is not an end itself. It is rather a means to attain certain ends, and therefore it constitutes an instrumental practice. Obviously, every instrumental practice is partly defined by virtue of the end to which that practice is oriented and relative to which the very practice is established. Disagreements as to what ends define a certain practice usually imply discrepancies about how to understand such practice. As any other cognitive activity, science is often broadly described as oriented towards the end of acquiring knowledge. Again, depending on how we understand knowledge, we will characterize science (in the sense of scientific practice) differently (cf. Kitcher 1992, pp. 103-104). For example, if we thought that knowledge entails a true, well justified description of reality, then scientific practice, as the means to attain such end, would be destined to provide conclusive evidence for descriptions. If, on the other hand, we understood knowledge as equated to the ability of successfully adapting to our environment, scientific practice would then be intended as a tool to determine which behavior would be dangerous and which profitable given a certain environment. Furthermore, in some cases talk about knowledge is altogether avoided as a consequence of rejecting any talk about truth, since, according to the traditional definition, knowledge is true well justified belief. Let us recall that Peirce, for intance, considered the fixation of belief as the ultimate goal of cognitive activity, emphasizing at the same time the adaptative value of belief fixation, ${ }^{1}$ and also that more recently B. C. van Fraassen argued for the primacy of empirical adequacy over truth as a goal of scientific theorizing.

Regardless of which specific choice and definition of an end we are assuming, it seems obvious that every practice oriented to a certain end can be performed either successfully or unsuccessfully. In this context, the notion of success must be understood in its informal, ordinary sense, as a function of utility in goal achievement. This characterization of success presupposes an instrumentalist context of evaluation where success is regarded as a property of practices, and the latter are, in turn, considered as means to attain certain valuable goals. To put it in N. Rescher's terms, success entails "benefit-producing practices" (1977, pp. 71-72), that is, effective procedures to obtain intended goals. Ultimately, then, evaluating success implies, not only a pre-

\footnotetext{
1 Peirce's point of view is clearly stated in the following quote:
}

\footnotetext{
"With the doubt, therefore, the struggle begins, and with the cessation of doubt it ends. Hence, the sole object of inquiry is the settlement of opinion. We may fancy that this is not enough for us, and that we seed, not merely an opinion, but a true opinion. But put this fancy to the test, and it proves groundless; for as soon as a firm belief is reached we are entirely satisfied, whether the belief be true or false. And it is clear that nothing out of the sphere of our knowledge can be our object, for nothing which does not affect the mind can be the motive for a mental effort. The most that can be maintained is, that we seek for a belief that we shall think to be true. But we think each one of our beliefs to be true, and, indeed, it is mere tautology to say so" (Peirce 1877/2006, pp. 114-115, italics in the original).
} 
vious determination of the intended goals, but also a comparative strategy to assess the relative superiority of a practice with respect to others in terms of goal achievement effectiveness. When the success is not achieved by chance, but because of that practice proving most effective, the properties on which that effectiveness is grounded constitute also the basis for a corresponding norm concerning how a practice must be in order to guarantee the attainment of a certain end, or at least to significantly increase its likelihood.

As for the scientific norms, they will be understood as action-oriented prescriptions, and therefore as drastically different from social or linguistic norms, many of which are not prescriptive but constitutive, providing conventions on which basis a certain practice is constituted. Grammatical norms, for example, are in the first place conventions establishing, not how a language should be, but how it is going to be. Similarly, social norms, like shaking hands when we are introduced to somebody, are not ultimately prescribing how a greeting should be, but rather constituting a convention about what a greeting is going to be. Scientific norms, by contrast, establish how an already existing practice should be in order to be successful, for this reason they are essentially prescriptive norms. It must be noted that, strictly speaking, the socalled 'prescriptive' and 'constitutive' norms are both normative, i.e., in a way both are trivially prescriptive, for it is clear-actually it is analytically true-that a norm is always normative. The important point, however, is that they are so in two quite different senses. In the case of social conventional norms, we should follow the norm, not because it provides the best way to do something, but just because it is a shared, agreed convention to do something in the way captured by the norm. In the case of scientific prescriptive norms, by contrast, we should follow the norm because it provides the best, most successful way to do something. Any norm, thus, establishes how a practice should be done, yet the normative (the "should") element can be justified either by virtue of a convention - as in the case of constitutive norms - or on the basis of a means to ends successful relation-like in the case of prescriptive norms. The distinction is important not only to avoid ambiguities, especially when using terms, like 'norm', with an extremely broad meaning, but also to properly restrict the scope of the present discussion to prescriptive, non-conventional scientific norms. Conventional norms, even if also relevant to scientific methodology, are not the ones discussed here.

Now, norms pervade cognition, not only exhibiting different characters, but also appearing in different modalities and even operating at different levels. There are, indeed, implicit and explicit norms, actual or possible, as well as norms related, for instance, to scientific practice and norms related to the study or philosophical approach to that scientific practice. The interaction between these distinct aspects is highly complex, since both actual and possible norms may be subject to implicitness or explicitness, and may be operating in science or in the philosophical inquiry into science. Actual norms guiding scientific practice are often implicit in such practice. In that case, part of the philosopher's job is to identify them and make them explicit. But this job can be supplemented by a more ambitious one, namely, conjecturing what possible norms could be more adequate than actual norms in order to achieve a certain pre-established end (i.e. what Kitcher calls the meliorative project in epistemology, 1992, p. 76). Granting, for now, that there are no substantial disagreements as to what actual norms exist, there still arises the problem of the enormous variance between 
philosophical hypotheses regarding possible norms, a problem which leads us back to that related to norms guiding philosophers in devising these hypotheses.

Summarizing some of the above issues, it is worth emphasizing that discrepancies about norms guiding science may have two different, general sources: one related to how cognitive ends are conceived, the other connected to what possible norms should be acknowledged as superior once that certain ends have been commonly acknowledged as the main cognitive goals. More generally, problems related to prescriptive norms for instrumental practices may arise from disagreements concerning either the definition of the ends or the definition of the success conditions for attaining certain pre-established ends (or they may arise from both things). With respect to the first possible problem, and as a minimal restriction, I am going to assume the priority of epistemic ends, since the accomplishment of non-epistemic purposes, like survival, adaptation and welfare, usually depends, in turn, on the attainment of epistemic ones, for instance observation, prediction and explanation. This asymmetric dependence relation between epistemic and non-epistemic purposes accounts for most familiar cases where, in order to satisfy some practical interests, some previous epistemic interests must be satisfied. For instance, if we seek to adjust our behavior to the climate conditions of a certain location, first we need to observe and predict those conditions. These intuitive comments are, of course, not intended to settle the intricate issue of the purpose of science, but they are rather directed to show part of the motivation to restrict the scope of the present discussion to epistemic norms. As for the problems concerning the definition of the means to attain certain pre-established ends, I will consider two main philosophical trends confronting them: the apriorist and the naturalistic (Laudan 1990, p. 47). According to apriorists (like Aristotle, Descartes, or Kant), norms are established by reflection on our cognitive capacities, that is, they are grounded on a priori theses about such capacities -like the Cartesian thesis that clear and distinct ideas are the basis for any further knowledge acquisition, or the Kantian idea that time and space are the pure forms of experience. Contemporary naturalists like Laudan and Kitcher, by contrast, regard norms as empirical and therefore as based on empirical facts about success in practice. The naturalistic approach to cognition is characterized by its skepticism towards the adequacy of a priori justifications of norms as well as of any other kind of theses in general. ${ }^{2}$ As discussed below, a basic, apriorist presupposition called into question by the naturalists is the thesis that we have transparent access to our own cognitive goals and norms. The naturalistic view is the one endorsed here. In particular, I will adopt the naturalistic assumption that non-casual success of scientific procedures is guaranteed (or, at least, its likelihood is increased) by virtue of such procedure having certain properties that are empirically determinable.

Norms are usually characterized as pragmatic if they are adopted for reasons regarding usefulness. However, without denying that aspect of pragmatic norms, it is possible to identify a deeper distinctive feature of them: the underlying idea that action or, more accurately, interaction provides the grounds for objectivity. Sound scientific inquiry

\footnotetext{
${ }^{2}$ Let us recall what Kitcher regards as one of the main theses from naturalistic epistemology: "Virtually nothing is knowable a priori and, in particular, no epistemological principle is knowable a priori" (1992, p. 76).
} 
requires intervention in the phenomena under study, which, in turn, entails either strengthening or weakening our expectations depending on the results prompted by the intervention. It is this idea what explains the emphasis placed on self-correction and experimentally controlled prediction by scientifically-oriented pragmatists like C. S. Peirce, G. Vailati or, more recently, by Rescher. When expectations have been challenged by the results of interaction, belief revision is one way to proceed, although there are other options like examining the evidence, or any of the different elements involved in the interaction. Pragmatic norms, therefore, not only maximize usefulness, they also maximize objectivity by establishing some methodological requirements concerning praxis.

What I will try to do in the following is to make explicit those pragmatic norms successfully governing science as a contribution that scientifically-oriented pragmatism can make to the normative naturalistic project in epistemology.

\section{The naturalistic approach to scientific norms}

As suggested above, the pragmatist contribution to the study of scientific methodology, especially that due to scientifically-oriented pragmatists, is better understood within a naturalistic philosophical frame. There are three basic points in which epistemological naturalism and the above kind of pragmatism agree: the anti-apriorism in epistemology, the challenge to the Cartesian test of certainty because of its being based on the individual consciousness, and the conception of epistemology as being in continuity with natural science. Let us briefly consider each of these points.

Advocates of epistemological naturalism, whether normative naturalists like J. Kim, P. Kitcher and L. Laudan or radical naturalists like W. V. O. Quine, D. M. Armstrong or P. Churchland, agree that epistemology, that is, knowledge about knowledge is $a$ posteriori. Pragmatists have traditionally emphasized that inquiry is a kind of practice, and thus also refused any a priori justification of knowledge, pointing out the justificatory role of practice. Furthermore, naturalists as well as pragmatists hold the view that we cannot get a reliable access to our own cognitive states just through reflection, thus rejecting the Cartesian ideal that we have reliable introspective access to the normative standards that guide our inquiries. By contrast, they recognize the trust in our cognitive habits as a key factor to ensure that our evaluations spread through our system of beliefs in an appropriate way. In his "Some Consequences of Four Incapacities" (1877a/2006), C. S. Peirce developed an extensive criticism of the Cartesian test of certainty because of its being based on the individual consciousness. There he draws the philosophical consequences that follow from several anti-Cartesian theses advocated by him, paying special attention to the one stating that: "We have no power of Introspection, but all knowledge of the internal world is derived by hypothetical reasoning from our knowledge of external facts" (ibid., p. 72). In a similar vein, a current pragmatist philosopher like C. Hookway draws a distinction relevant for the present discussion, since it suggests the possible difficulties emerging from the task of norms recognition:

"An important distinction can be drawn between:

1. Those norms and patterns of evaluation which guide us in the conduct of activities including those of inquiry and investigations 
2. Those norms and standards of evaluation which we believe are guiding us in these activities" (1999, p. 215).

Following a norm and believing that we follow a norm are mutually independent phenomena. Three different cases constitute the evidence for asserting this independence: 1. people ignore they follow a norm, 2. people wrongly think that they follow a norm, 3. people wrongly think they do not follow a norm. On the other hand, the thesis that epistemology is in continuity with natural science means that, in order to study knowledge acquisition and justification, we should apply a scientific methodology. The above considerations suggest that norms governing knowledge acquisition and justification must be established a posteriori, rather than by an a priori, introspective access to them.

Now, naturalistic epistemology is an extraordinarily wide field, so it can be helpful to distinguish between different naturalistic attitudes towards the normative, and to identify the one that best matches the above pragmatist attitude. By partially relying on J. Maffie's account of epistemological naturalism (cf. 1990, pp. 284-287), three distinct alternatives will be examined. The first is Quine's eliminative naturalism, according to which epistemic norms should be replaced with descriptions of natural facts about the causal-nomological relations between sensory input and theoretical output. From the second approach, that is, Laudan's normative naturalism, epistemic norms are regarded as reducible to descriptions of facts about means-ends instrumentally appropriate relationships. More particularly, epistemic norms would be hypothetical imperatives linking means and ends on the basis of empirically determined success. Finally, there is Kim's and Kitcher's criterial naturalism, from which epistemic norms are characterized as supervening upon natural, cognitive facts. Such facts would be reasons for adopting the corresponding norms:

"(...) if a belief is justified, that must be so because it has a certain factual, nonepistemic properties, such as perhaps that it is "indubitable", that it is seen to be entailed by another belief that is independently justified, that it is appropriately caused by perceptual experience, or whatever" (Kim 1988, p. 310, italics in the original).

It is interesting to realize that, depending on which kind of naturalism we endorse, we will be either openly committing the naturalistic fallacy (like in Laudan's case), or avoiding it, in one case by ruling out the normative dimension (like in Quine's approach), in the other by appealing to the notion of supervenience (as Kim or Kitcher do). Pragmatists like Peirce and Vailati are clearly intending something else than describing cognitive processes, they are rather laying down substantially normative theses. As a consequence, their view is closer to that held by Laudan and criterial naturalists, and, among these two remaining approaches these pragmatists seem closer to criterial naturalism. The reason for that is that they openly commit to certain theses regarding our cognitive nature, not to be found in Laudan's case, who keeps the epistemological analysis anchored to the single principle of instrumental success. According to Peirce and Vailati, interaction with the environment as well as the resulting expectations and actions set the stage in which the epistemic performance takes 
place. Any normative proposal concerning inquiry needs to rest on criteria related to this cognitive nature.

No argument will be put forward here to defend the superiority of naturalism over other more traditional approaches, since it may even be convenient not to give up any of them altogether. However, if we recognize that a broad epistemological naturalism can be helpful in accounting for knowledge or cognitive achievements, then it may be useful to also consider some interesting contributions that pragmatism can make to the naturalistic project in epistemology. The present paper deals with the pragmatic contribution to answering the above normative questions, which represents a step towards a more developed normative naturalism.

\section{The nature of pragmatic norms: some seminal ideas from Peirce, Vailati and Quine}

Let us now pay attention to what may be the most distinct feature of pragmatic norms, namely, the assumption that action or, rather, interaction provides the grounds for objectivity. This assumption ramifies in various philosophical claims, among them, the idea that manipulating entities or phenomena is the best way to develop valid beliefs about them, or the view that valid beliefs must secure successful action. Both objective existence (i.e., according to pragmatists, the only meaningful conception of reality) and objective, epistemic success depend, for their determination, on the essential test of action. The first (connection) is accounted for by the fact that properties of objects are only detectable through cause and effect relations, which, in turn, are only soundly determinable by manipulation. The second has to do with the concrete consequences that a true belief should support. According to Peirce, the scientific method of inquiry is better than the others because it is deliberately designed to arrive at the ultimate most secure beliefs, upon which the most successful actions can be based. ${ }^{3}$

It must be pointed out that the above questions concerning the justificatory aspect of practice derive from a more basic one related to the constitutive role that, according to pragmatists, practice plays in experience. In this conception of experience lies precisely one of the key differences between two empiricist traditions represented by pragmatism and neopositivism respectively. Pragmatists reject any passive conception of experience according to which the latter should be explained in terms of sense-data or some macroscopic, stable objects or properties. By contrast, they developed an active conception of experience where no element or aspect is acknowledged as given, basic, but instead action is regarded as always entering in our experience of the environment. Also, the more scientific the experience is the more dependent on specific

\footnotetext{
3 Peirce's appeal to experimental practice emerges already in his formulation of the pragmatic maxim:

"(...) a conception, that is, the rational purport of a word or other expression, lies exclusively in its conceivable bearing upon the conduct of life; so that, since obviously nothing that might not result from experiment can have any direct bearing upon conduct, if one can define accurately all the conceivable experimental phenomena which the affirmation or denial of a concept could imply, one will have therein a complete definition of the concept, and there is absolutely nothing more in it. For this doctrine he [Peirce] invented the name pragmatism" (Peirce 1902-1907/2006, p. 162).
} 
actions carefully performed. All classical pragmatists agree that experience is always active and inferential, shaped by interactions with surroundings and by the corresponding habits of expectations. As a result of this important difference between pragmatists and neopositivists, the latter have undertaken the task of formulating norms concerning how observational assertions should support theoretical ones, whereas the former have suggested norms related to how any kind of assertion, whether highly theoretical or seemingly of a basic, observational nature, must be validated in practice. ${ }^{4}$ The emphasis placed on the role of intervention in yielding empirical meaning is common to both operationalism and pragmatism, whose respective accounts of meaning managed to supersede the sense-data approach as well as the crude physicalist one (Evans 1939, p. 424). Despite this connection between the two accounts, however, it is quite obvious that operationalism constitutes a reductionist approach to meaning and that nothing of that kind is pursued by pragmatists. On the other hand, the decided, multidimensional appeal to practice also explains two other typical features of pragmatism that are noticeable in the pragmatic norms: the transverse character of its principles, manifest in the possibility of recognizing pragmatic accomplishments even if provided from divergent theoretical approaches, and the neutrality toward foundational issues due to the latter going beyond what can be settled through practice. ${ }^{5}$

The first main supporters of a scientificist pragmatism, i.e. Peirce and Vailati, did not make explicit any particular set of norms that would be reponsible for ruling scientific practice. Yet, they both emphasized what they understood as some of the primary methodological characteristics of empirical science. Peirce famously drew attention to the importance of self-correction for a practice to be considered scientific, and, as it has been pointed out by latter pragmatists, this very requirement implies many others, like the reliability of experimental practices or the study and control of experimental error, just to mention a couple of examples. It is also well-known the Peircean emphasis on convergent results coming from different views and methods of identity as the sign of truth as well as of reality. Independence from the human mind would be the main feature of reality, and such feature would not only be manifest in the independent cause of sensations, but also in the fact that our opinions are constrained and forced to converge (cf. Peirce 1877/2006, p. 122; 1878/2006, pp. 146-147). ${ }^{6}$ In

\footnotetext{
4 The present use of the term 'validate' rests on an extensive tradition from the literature on empirical research methodology, where 'validity' does not have a logical sense, but an epistemological one. In his classic reference work from 1989, S. Messick develops the notion of (theoretical) construct validity, more widely referred to by other authors as hypothesis validity, like in Robert W. Lissitz's (2009) The Concept of Validity: Revisions, New Directions, and Applications. Within this framework, validity and reliability are regarded as logically independent notions, even if commonly associated properties of measurements and procedures. Reliability has to do with the consistency of the outcome, while the validity concerns the degree of success in attaining the purported outcome (that is, in determining the variable under study).

5 The above features of pragmatism have been stressed by P. Suppes in arguing that the focus on practice as opposed to foundations is clearly recognizable in modern physics (cf. 1998, pp. 237-238, 246-251).

6 The next two quotes provide some textual evidence on this subject:
}

"Our external permanency would not be external, in our sense, if it was restricted in its influence to one individual. It must be something which affects, or might affect, every man. And, though these affections are necessarily as various as are individual conditions, yet the method must be such that the ultimate conclusion of every man shall be the same. Such is the method of science" (1877/2006, p. 122). 
fact, such independence would be ultimately established through the recognition that external things are inter-subjectively determined and therefore not just determined by individual minds.

As for Vailati, his main focus was on the predictive conditions for cognitive significance together with that on the practical or operational requirements both to generate and validate predictions. Predictability would be the crucial pre-condition to determine both truth and meaning (cf. Vailati and Calderoni 1909/2010, pp. 249, 255). Experience is therefore ascribed a double role (epistemic and semantic): providing the means to verify a theory, as well as those to determine the part of the theory that is meaningful and can therefore be object of useful discussion. The pragmatic method does not provide a criterion to decide whether an assertion is true or false, but just a criterion to determine the part of an assertion's content that is necessary (though not sufficient) to decide whether the assertion is true or false. The better the predictions implied by such part are in terms of precision, extension, and possibility of refutation, the more profitable that the discussion of that theory can be. Vailati distinguishes between two basic kinds of expectations: proper (or effective) expectations that some event will happen, and conditional expectations, which consist in predictions that some event would happen given other previous conditions (cf. Vailati and Calderoni 1909/2010, pp. 251-253). The two kinds of expectations are related in the following way: a conditional expectation whose condition has been satisfied is necessary for a proper expectation. The latter, therefore, depends on the former, more precisely, on the former's condition being verified or waited for. There would also be different kinds of conditional expectations depending on the sorts of conditions involved. Vailati distinguishes between conditions that consist in some deliberate acts of ours and those that do not so. Only the former would be essentially involved in judgments about existence or in attribution of properties. These judgments are based on the belief in a necessary connection between experiences produced by a voluntary act of ours and that act, that is, the belief that certain experiences can only be obtained by means of certain deliberate actions on our part. When we believe that this connection is contingent, or we consider that those experiences are rather connected to certain conditions which are not produced by us, then we just form the belief that there is a concatenation between some facts or, at most, that there is a cause-effect relation between them. In short, experiences on the basis of which we assert existence are only obtained by means of

Footnote 6 continued

The same idea is stated as follows:

\footnotetext{
"On the other hand, all the followers of science are fully persuaded that the processes of investigation, if only pushed far enough, will give one certain solution to every question to which they can be applied. One man may investigate the velocity of light by studying the transits of Venus and the aberration of the stars; another by the oppositions of Mars and the eclipses of Jupiter's satellites; a third by the method of Fizeau; a fourth by that of Foucault; a fifth by the motions of the curves of Lissajous; a sixth, a seventh, an eighth, and a ninth, may follow the different methods of comparing the measures of statical and dynamical electricity. They may at first obtain different results, but, as each perfects his method and his processes, the results will move steadily together toward a destined centre. (...) This great law is embodied in the conception of truth and reality. The opinion which is fated to be ultimately agreed to by all who investigate, is what we mean by the truth, and the object represented in this opinion is the real" (1878/2006, pp. 146-147).
} 
certain deliberate action on our part; otherwise we could simply be justified to believe in a certain relation between facts. ${ }^{7}$ The key issue with respect to judgments about existence is not just what a subject has to do right before making such judgment, but what one knows one would have to do to make sure about attributing existence to something. Of course, once we have a good training in determining the existence of certain things, we can make sound inferences about existence when confronted with similar cases. Let us note that Vailati's account is focused on sound existence judgments, rather than on existence judgments regardless of their epistemic support. From the above discussion, Vailati reaches the following normative conclusion: assertions about existence must be translatable into certain kinds of expressions that refer to a certain kind of conditional expectations. This claim, again, should not be interpreted in any reductionist sense, for that kind of translation is not regarded as providing the whole meaning of an assertion but only its the empirical content- this represents, in fact, one of Vailati's refinements of the Peircean semantic view.

Despite the rich material that Peirce and Vailati supplied for the project of identifying the basic pragmatic norms guiding the scientific activity, the only author who made an explicit and systematic reference to pragmatic norms was Quine, ${ }^{8}$ - who, in spite of his recurrent vindication of pragmatism in many of his works, neither appealed to any pragmatist author, nor to any typical pragmatist thesis, in his contribution to the present subject. His worries about confirmation holism and the underdetermination of theories by evidence-previously discussed by him in "Epistemology Naturalized" (1969), provided the background behind his formulation of the pragmatic norms. Such worries, in turn, connected to some initial semantic problems concerning the inscrutability of reference and the indeterminacy of translation-which were extensively addressed in his Word and Object from 1960. According to him, belief revision should be guided by pragmatic norms, whose scope would also cover all theory formulation and hypotheses generation, since these would amount to instances of belief revision. The pragmatic norms would thus be heuristics that assist the scientist in belief revision and hypothesis generation by supplementing purely inductive and deductive methods. Quine distinguishes six pragmatic norms: conservatism, modesty, simplicity, generality, refutability and precision. The first is also called by Quine as the "maxim of minimum mutilation" (1990/2003, pp. 14-15), and it establishes the following: "The less rejection of prior beliefs required, the more plausible the hypothesis - other things being equal" (1970/1978, p. 67). The norm concerning modesty favors hypotheses that

\footnotetext{
7 Vailati's modal talk about necessary versus contingent connections between events should not be understood in metaphysical terms. According to his view, the kind of necessity supporting certain kind of conditional expectations is the same as the one supporting sound counter-factual inferences. In this context, the distinction between necessary and contingent connections between facts is not established on metaphysical terms, but rather on experiential terms related to the grounding of counter-factual inferences. More precisely, Vailati argues that only conditional expectations whose condition consists in some deliberate acts support counterfactuals. In contrast, conditional expectations formed independently of deliberate acts would just support the belief in contingent connections between facts.

8 Of course, scattered references to pragmatic values like predictive power and simplicity can be found in works by other authors (this is especially clear in the case of T. S. Kuhn). Among those values, simplicity has been traditionally emphasized and more carefully characterized, as R. Carnap's early formulation of the principle of maximal simplicity suggests. Yet, before Quine, no attempt was pursued to provide a systematic account of the pragmatic norms governing science.
} 
are logically weaker and conceptually familiar (cf. ibid., p. 68). The norm of simplicity, which would include Ockham's razor principle, is stated as follows: “(...) when choosing a hypothesis subject to subsequent correction, it is the best to choose the simplest that is not yet excluded" (ibid., p. 72). As for the norm of generality, it says that our beliefs or hypotheses should be articulated with sufficient generality so that our initial experimental results will hold in subsequent test situations even though the latter do not correspond exactly to the first experimental run (cf. ibid., pp. 73-76). The norm regarding refutability establishes that the greater the cost of retaining previous beliefs in order to save a hypothesis, the more refutable the hypothesis (ibid., p. 79). Finally, here is the norm of precision as formulated by Quine: "The more precise a hypothesis is, the more strongly it is confirmed by each successful prediction that it generates" (ibid., p. 98).

The Quinean formulation of the pragmatic norms, even if plausible, is clearly lacking in accuracy and exhaustiveness. The reminder of this paper is focused on the project of developing a formulation of the pragmatic norms more systematic and comprehensive than the ones suggested so far. The present account, therefore, includes several norms that had apparently remained ignored by Quine, perhaps partly due to the fact that he still restricts his study to theories and hypotheses justification, thereby joining the traditional neglect of practices. This approach also departs from his in the assessment of some of the theoretical virtues he mentions. In particular, simplicity and modesty are here considered as questionable virtues, since, putting computation aside, there is no clear evidence that simpler, more modest theories are more likely to be successful than the others. The application of the norm concerning simplicity is best restricted to computational issues because, as Popper noted decades ago, a stronger, more informative theory-and therefore one more likely to be false-can be more interesting than a weaker, less informative theory-that is more likely to be true. Given the controversy surrounding simplicity, norms concerning the latter are going to be restricted to the sphere where it is clearly beneficial, namely, the sphere of computation.

\section{Making explicit the pragmatic norms}

As already pointed out, the pragmatic norms are here established from a naturalistic approach that proves especially sensitive to the role of action in scientific research. Norms are understood, in this context, as principles abstracted from successful practice. There are some problems posed by the notion of principle, since it seems to involve explicitness or, at least, some potential explicitness as a characteristic property of the principles. However, even if potential explicitness is not granted as a necessary condition for norms to be acknowledged, the explicitness of norms, when attainable, may be extremely helpful in developing a sound scientific methodology. As an effort in that direction, some pragmatic norms are made explicit this section. In doing that, no mention is made to Popper's classical distinction between context of discovery and context of justification - also drawn by Reichenbach, Carnap, and Schlick, among others. The reason for this absence is that such distinction can be questioned on several different grounds, becoming clear that the context of discovery constitutes also a context of 
justification. Once that the notion of justification is not restricted to that of examining the logical connections between statements, the process of devising a new conjecture and that of examining its justification should not be regarded as necessarily separate ones. But even if we favoured the logical version of justification, as N. R. Hanson has convincingly argued, there are relevant logical aspects involved in hypotheses generation. In fact, the two contexts have been shown to overlap in different ways: on the one hand, some important features of the context of justification should be studied empirically, since the logical analysis will not suffice (T. S. Kuhn, W. V. O. Quine), on the other hand, some relevant aspects of the context of discovery are amenable to logical study (Hanson, and some recent followers like P. Thagard or A. Aliseda). Given that no interesting, clear-cut distinction can be drawn between the two contexts, the norms formulated below are not arranged accordingly.

For the formulation of the norms I have mainly relied on the previous ideas developed by Peirce, Vailati and Quine, as well as on further support to such ideas provided by the work of contemporary philosophers of experimentation and methodologists of science. The norms will be divided into four non-mutually exclusive, partially independent classes corresponding to four basic goals in science. Norms related to self-correction and prediction will be regarded as preeminent to those related to explanation, experimentation and computation. As already suggested in dealing with Vailati's account of conditional expectations, prediction derives this pre-eminence from its key role as a source of objectivity for both experience and the validity of scientific conjectures. Following the usual practice in current literature, retro-dictions are here acknowledged as a kind of prediction, more specifically, as predictions about the past, which prove essential in sciences like palaeontology, archaeology and cosmology. ${ }^{9}$ The primacy of self-correction, on the other hand, stems from the fact that the latter guarantees the possibility of improving any element of the scientific inquiry, and therefore the general norms regarding self-correction apply to all the other aspects of the scientific practice. Furthermore, it must be stressed that prediction and self-correction turn out to be intertwined in their basic methodological roles. Self-correction involves to a great extent the resort to predictions, and conversely predictions are also subject to self-correction. Essential pragmatic norms relative to explanation, experimentation and computation have to do with requirements concerning prediction and the possibility of self-correction. In other words, norms meant to improve the three former aspects of science necessarily imply considerations of predictive and self-correcting underlying elements, while the converse is not the case. This is not denying that theoretical explanations may sometimes play a valuable guiding role in suggesting new predictions, and even less that predictions themselves can be understood as a form of explanation. The emphasis, however, is here to be placed on prediction as the key element involved in the empirical justification of both theories and procedures.

The different classes of norms, therefore, correspond to different essential aspects of scientific practice connected by a preorder relation of dependence, thus yielding a partial, weak hierarchy. This means that subordination here holds only between certain classes of norms and satisfies transitivity, being also possible that subordi-

\footnotetext{
9 This widely accepted view that has been developed, for example, by P. Lipton in his work from 1991/2004, p. 169).
} 
nation between certain subclasses satisfies reflexivity and symmetry. The epistemic pre-eminence of predictive success is clearly acknowledged in Quine:

"But the ultimate objective is so to choose the revision as to maximize future success in prediction: future coverage of true observation categoricals. There is no recipe for this, but maximization of simplicity and minimization of mutilation are maxims by which science strives for vindication in future predictions" (1990/2003, p. 15).

The priority of predictive success is advocated also in Almeder's formulation of the general pragmatic principle concerning the rational justification of scientific beliefs:

"One way to express more succinctly the pragmatic principle (PP) implied by all this is as follows: Assuming that $P$ is a proposition about the world,

PP. A person is justified in accepting $P$ as true

(a) if $P$ is either soundly inferred directly by inductive or deductive inference from other known or justified beliefs; or

(b) if when $P$ is not so soundly inferred, there is some real possibility that accepting $P$ as true will tend to be more productive of explanations and precise predictions than would be the case if one had accepted instead either the denial of $P$ or nothing at all" (2008, p. 91).

The reference to explanation should not mislead the reader, since Almeder himself goes on to clarify that good explanations must generate precise predictions of sensory experiences, thereby pointing to accurate predictions as the final grounds for scientific belief justification.

Those pragmatists or philosophers of experimentation providing arguments for laying down the pragmatic norms appear mentioned between brackets. It goes without saying that the following list is tentative and not intended as exhaustive. In view of the current controversy surrounding methodological lists for scientific experimental inquiry, ${ }^{10}$ it may be appropriate to emphasize the systematic character of the present one, which derives from the recognition of basic epistemic goals and their respective dependence relations. One more qualification must be added. Given the instrumental character of the pragmatic norms, they should be formulated by means of conditional sentences of the form: 'If goal $x$ is being pursued, then procedure $y$ should be

\footnotetext{
10 This controversy results from what Hacking calls the "etc. list problem"- that is, the lack of systematicity in the characterization of experimental practice-, and would involve authors like E. Mach, A. Pickering, D. Gooding, G. Hon, A. Franklin, and R. Harré, among others. Hon argues that recent attempts at formulating epistemological or experimental principles for scientific inquiry have been misguided due to their extremely ad hoc and eclectic character (cf. 2003, pp. 266-268). She examines the different accounts by R. Harré, A. Franklin and I. Hacking respectively, to conclude that all of them are too fragmentary, for they focus either on particular experimental goals or on certain experimental elements without clarifying which guiding principle should govern the list itself. Her Baconian proposal consists in approaching experiment from the consideration of possible sources of error (cf. 276-281). According to her, the latter could be of either of the following classes: script (design), stage (setting), spectator (scientific agent) and moral (interpretation). Despite the perceptiveness and fruitfulness of Hon's account, the inquiry into the sources of error is not the only way to secure the systematic character of an intended list of epistemological principles. Here I provide another way to attain the same end, in this case through the organization of basic epistemic goals into a partial hierarchy.
} 
employed'. For the sake of simplicity, the conditional form will not be used in the formulations, for it seems fairly straightforward to figure out the conditional sentence corresponding to each norm. Just to avoid any confusion: norms related to self-correction would be conditionalized to this very goal, those related to prediction would be conditionalized to the latter, and so on.

I now turn to the formulation of some pragmatic norms that I consider soundly supported by a careful observation and analysis of scientific practice.

\subsection{Norms related to self-correction}

Norms related to self-correction are intended to depict those basic requirements that guarantee the self-corrective character of science. As it is well-known, Peirce pointed to such character as the key distinctive feature of the scientific method, whose superiority would be owing to its efficacy not only in belief revision but also in method correction. This reflexive feature of scientific method is emphasized by Peirce in the following way:

"But with the scientific method the case is different. (...) The test of whether I am truly following the method is not an immediate appeal to my feelings and purposes, but, on the contrary, itself involves the application of the method" $(1877 \mathrm{~b} / 2006,123)$.

The possibility of self-correction, in this context, comes from several experimental factors of which Peirce was very aware. He draws special attention to repeatability, manipulability, reliability, error control, independent evidence, and convergence in results. It is because the scientific method exhibits these features that it has a selfcorrective nature. Put it differently, the application of the scientific method can itself be tested by applying the method, that is, by repeating, manipulating, controlling the errors, etc., of the procedure under test. It seems obvious that the above experimental factors become essential goals of scientific inquiry by virtue of their crucial methodological role.

Norms related to self-correction are presented next.

* To manipulate the object under study (cf. Vailati and Calderoni 1909/2010, pp. 250-257; Franklin 2005, Chaps. 13-14). Our knowledge of an object depends on the possibility of finding out that it reacts in systematic ways under intervention. The open range of possible manipulations guarantees the open range of possible corrections of our conception of the object.

* To devise observational procedures, measurements, experiments that can be repeatable (cf. Peirce 1877b/2006, pp. 122-123). The repeatability of those procedures is essentially required in order to assess their reliability. The latter concerns the extent to which an experiment, test, or any measuring procedure yields the same results in repeated trials under the same conditions. In other words, it consists in the degree to which repeated measurements of the same phenomenon tend to be consistent with one another. 
* To subject the experimental apparatus to calibration and to reproduce artifacts (Franklin 2005, Chaps. 13-14). This norm amounts to the requirement of selfcorrection applied to instruments.

* To avoid noise and confounds (Messick 1989, pp. 28-33). In order to find out which of the various parameters affect a given effect, and which of them are essentially required to prompt such effect, it is required to systematically change experimental parameters.

* To devise careful simulations of errors that "make them talk" (Mayo 1996, p. 36). This would make possible, in turn, to devise a severe tests for a hypothesis, and ultimately to come up with experimental tests which make possible a rational choice between alternative hypotheses. Some recent literature on "deficit studies" provides also some interesting insights into how the deliberate creation of structural failures in a system may help to further explore such system (cf. Craver 2002, pp. S12-S13, Bechtel 2002, pp. S51-S53).

* To avoid possible bias prompted by the use of a single procedure by performing multiple measures of each theoretical construct under scrutiny (Peirce 1878/2006, pp. 142, 146-147; Messick 1989, p. 65). This norm is meant to foster convergence of results, since convergent evidence shows that the measurements inter-correlate as implied by the theory.

\subsection{Norms related to prediction}

Pragmatic norms concerning prediction would help to ground existence assertions on well supported conditional expectations, to put it in Vailati's terms. Some of the main goals to foster in relation to prediction are precision, explorative efficacy, testing efficacy, all of them related to the robustness of predictions. The following two norms related to prediction must be taken into account.

* To favor laboratory controlled predictions over field predictions, since only the first provide enough grounds to ascertain a non-contingent relation between events (Peirce 1902-1907/2006, p. 162). Again, this has to do with the role that manipulation must play in predictions in order for them to convey valuable information about objects and events.

* To increase the number of significant predictions, not only to test a particular theory or to support causal explanations, but also to determine empirical regularities (Steinle 1997, pp. s65-s66). Steinle convincingly argues that there are different ways to engage in experimental practice, being theory testing just one of them. In particular, he distinguishes between what he calls "standard experimentation" (focused on theory testing) and "exploratory experimentation" (focused on formulating regularities). The central experimental procedure characteristic of the latter would be the systematic variation of experimental parameters, in order to find out which of the various parameters affect a given effect, and which of them are essentially required to prompt such effect. According to him, exploratory experimentation is especially useful in concept-formation, since the attempt to determine regularities would often require the application of new categories. An example of 
observance of this norm is the predictions of the positions of the heavenly bodies during the Babylonian period.

\subsection{Norms related to explanation}

Tuning now to the norms related to explanation, the following associated goals should be mentioned: predictive efficacy, empirical adequacy, coherence, scope. Let us see how these goals shape the corresponding norms.

* To give (when possible) causal explanations that either prove predictively efficient or account for unpredictable phenomena. This norm is based on some ideas that Suppes presents is his 1985 paper "Explaining the Unpredictable", where he states: "For many phenomena in many domains there are principled reasons to believe that we shall never be able to move from good explanations to good predictions" (Suppes 1985, p. 194). As examples of those cases he refers to explanations of past events, random events (like quantum phenomena), or chaotic, instable events (like roulette wheel outcomes or human behavior). The key point in this norm is the emphasis on the predictive power of explanations, which is only restricted either by research limitations or by the very nature of events. Despite these restrictions, explanation remains more connected to prediction than it might seem at first, since, as pointed out by Suppes, successful explanations of unpredictable events usually consist in a specification of those parameters and causal relations that would have enabled predictions if they could have been specified in advance.

* To use (when possible) causal explanations that do not appeal to unverified causes, neither supernatural or religious nor metaphysical (Bertrand Russell's version of Ockham's razor). The creationism versus Darwinism debate exemplifies a clear opposition regarding this issue, for the creationist obviously appeals to an unverified, religious cause in order to explain how the homo sapiens appeared on the earth, while Darwinism resorts to verified causes. Aristotle's explanation of the stillness of the earth in terms of natural movement constitutes a clear example of non-observance of this norm (De Caelo, Book II, Ch. 13)).

* To devise hypothesis that cohere with previously existing successful hypotheses (Quine's conservatism). Seen from a different angle, this norm establishes that hypotheses should be devised in such a way that they were approximated by previous ones.

* To explain the same kind of phenomenon in terms of the same cause (Vailati 1907, p. 708). In a strict sense no facts repeat themselves, which implies that to assert that there is a causal relation amounts to saying "that effects which resemble one another constantly succeed causes which resemble one another" (ibid., italics in the original). This norm closely connects with Newton's second rule for scientific reasoning:

"Therefore to the same natural effects we must, as far as possible, assign the same causes" (1687/1848, Book III, p. 384). ${ }^{11}$

\footnotetext{
11 Book III begins with Newton's formulation of four "rules of reasoning in natural philosophy". Let us recall the remaining three:
} 
Incidentally, there is a common preconception about causal relationships that, as opposed to the former, is not empirically supported, namely, that the effect must be similar to the cause.

* To favor one theory over another when, ceteris paribus, the first is applicable in some new domain (Quine's generality norm).

\subsection{Norms related to experiments and computation}

Because of the partially overlapping nature of the present classification, there are some norms which do not appear here only to avoid redundancy (in particular, those regarding the threats of noise, confounds and bias). The main sub-goals involved in experiment and computation are: the test of empirical adequacy, scope and simplicity. The following four norms seem especially important.

* To avoid the empirical under-representation of theoretical concepts, that is, to set the relevant variables subject to determination in an experiment in such a way that reflects the breadth of the theoretical construct invoked in the interpretation of the experiment (Messick 1989, pp. 34-35). The evaluation of construct validity involves close examination of the auxiliary theory or theories specifying the relationship between concepts and empirical indicators. The purpose of this norm is clearly to increase the empirical robustness of theoretical constructs by increasing the number and soundness of their empirical indicators.

* To gather discriminant evidence that the measurement or experiment is not related to some other theoretical concept accounting for the results obtained (Messick

\section{Footnote 11 continued}

Rule I: "We are to admit no more causes of natural things than such as are both true and sufficient to explain their appearances".

Rule III: "The qualities of bodies, which admit neither intensification nor remission of degrees, and which are found to belong to all bodies within the reach of our experiments, are to be esteemed the universal qualities of bodies whatsoever" (added in the 1713 edition, ibid., pp. 384-385).

Rule IV: "In experimental philosophy we are to look upon propositions inferred by general induction from phenomena as accurately or very nearly true, notwithstanding any contrary hypotheses that may be imagined, till such time as other phenomena occur, by which they may either be made more accurate, or liable to exceptions" (added in the 1726 edition, ibid., p. 385).

In discussing Newton's rules, Barry Gower points out the following: "Newton used the first and second rules, usually together, to justify the claim that the 'same sort of cause', namely a gravitational force, must be responsible for the behaviour of heavy terrestrial objects, for the Moon's orbiting the Earth, for the planets' orbiting the Sun, and for the satellites of Saturn and Jupiter orbiting their planets" (Gower 1997, p. 71). Interestingly, shortly after the above remark, Gower notes that Newton hardly provided any justification for the rules, which are instead vindicated by the scientific results that they make possible to achieve. It may be worthwhile to compare Newton's second Rule with Hume's fourth rule for judging causes and effects: "The same cause always produces the same effect, and the same effect never arises but from the same cause. This principle we derive from experience, and is the source of most of our philosophical reasonings. For when by any clear experiment we have discovered the causes or effects of any phenomenon, we immediately extend our observation to every phenomenon of the same kind, without waiting for that constant repetition, from which the first idea of this relation is derived" (1739-1740/1964, Book I, Part III, Sect. XV, pp. 170-171). In neither case the rules of causation are grounded on metaphysical commitments regarding necessities in nature. In Newton's case, the justification seems rather pragmatic, and, in the case of Hume, it comes from the psychological laws of association formulated by him. 
1989, pp. 34-36). Put another way, the idea is to avoid that variance in test proves irrelevant to theoretical constructs, for in that case the constructs would include something that should be left out.

* To favor between two new experiments, ceteris paribus, the one that has more variation between the two (pragmatic principle of the variability or generality of experiments). The robustness of experiments significantly depends on the degree of satisfaction of this norm.

* To favour theories which are computationally simpler or more efficient, other things being equal (Quine's simplicity principle restricted to computation). An example of this is Ptolemy's choice of the eccentric circle system over the epicycle system after having proven their equivalence.

\section{Closing remarks}

Finally, to further clarify the above issues, I would like mention some common cases of non-observance of the pragmatic norms. According to such norms, obvious cases of flawed scientific practice are those in which traditional or metaphysical assumptions are kept despite their lack of empirical value (i.e., their being non-testable and not helpful in predictions), causal explanations of predictable phenomena are given despite their predictive inefficiency, generalizations are made even if they are empirically unsupported, empirical claims are discussed the same way as speculative claims (i.e., by equally examining every logical possible justification of the claim) regardless of well ascertained probabilities about empirical events that would help to rule out some of the possible justifications, and also those cases in which accommodations, instead of predictions, are employed to test a theory. The first case can be illustrated with the notion of vital principle used in biology and physiology from ancient times to the beginning of the XX century, despite its metaphysical, non-testable character. The second case may be exemplified with Aristotle's postulation of natural places to explain mechanical phenomena, a causal postulate which involves a predictively inefficient explanation of predictable phenomena. On the other hand, XIX century physiology is riddled with empirically unsupported generalizations about racial features, which illustrates the third case of pragmatically flawed inquiry. The marked speculative nature of Aristotle's main argument for the spherical shape of the earth constitutes an example for the next kind of case (let us recall that the argument developed deductively from the assumption that the earth and the universe have the same center). Finally, a famous case in which accommodations are employed, instead of predictions, is that of psychoanalysis, severely criticized by Popper.

The present formulation of the pragmatic norms is meant to capture those implicit principles which, by supplementing the traditional principles regarding deductive or inductive inferences, successfully govern scientific practice. The ultimate basis for a vindication of the pragmatic norms has to do with a connection emphasized by classical pragmatists between objectivity and experimentally controlled prediction. Such connection determines a partial hierarchy between different types of pragmatic norms, which implies that successful explanations, for instance, must satisfy stronger predictive requirements than it is usually acknowledged (i.e., requirements beyond 
conservatism). The justification of the pragmatic norms comes from a non-reductivist naturalistic approach according to which such norms, even if recognized just from actual instrumental success in practice, are nevertheless grounded on essential characteristics of cognition, like the basic relation between repeatable manipulation and expectation.

Acknowledgments I am thankful to Patrick Suppes for very helpful discussion on many of the issues addressed here, as well as for making me familiar with Vailati's work. Thanks also to Mark Dietrich Tschaepe and Ronald Giere for their valuable suggestions regarding an earlier version of this work, which was presented at the Pragmatism \& Science Conference (The Center for Inquiry, Amherst, NY). The final version of the paper has greatly benefited from extensive criticism by two anonymous referees of this journal. This work was financially supported by the Spanish Ministry of Science and Innovation through the following projects: Language and Thought: Context-Dependency (FFI2008-06421- CO2-02/FISO), Cognitive Attitudes and the Justification of Knowledge (FFI2009- 08828/FISO).

\section{References}

Almeder, R. (2008). Pragmatism and science. In S. Psillos \& M. Curd (Eds.), The Routledge companion to philosophy of science (pp. 91-99). New York: Routledge.

Bechtel, W. (2002). Aligning multiple research techniques in cognitive neuroscience: Why is it important?. Philosophy of Science, 69, S48-S58.

Craver, C. (2002). Interlevel experiments and multilevel mechanisms in the neuroscience of memory. Philosophy of Science, 69, S83-S97.

Evans, V. B. (1939). The pragmatism of Giovanni Vailati. International Journal of Ethics, 403, 416-424.

Franklin, A. (2005). No easy answers: Science and the pursuit of knowledge. Pittsburgh: University of Pittsburgh Press.

Gower, B. (1997). Isaac Newton: Rules for reasoning scientifically. In B. Gower (Ed.), Scientific method: A historical and philosophical introduction (pp. 63-82). London: Routledge.

Hon, G. (2003). An attempt at a philosophy of experiment. In M. C. Galavotti (Ed.), Observation and experiment in the natural and social sciences (pp. 259-284). Netherlands: Kluwer Academic Publishers.

Hookway, C. (1999). Doubt: Affective states and the regulation of inquiry. In: C. J. Misak (Ed.), Pragmatism. Canadian Journal of Philosophy (pp. 203-226). Calgary: University of Calgary Press.

Hume, D. (1739-1740/1964). A treatise of human nature (Vol. I). London: Dent.

Kim, J. (1988). What is 'Naturalized epistemology'? In E. Sosa \& J. Kim (Eds.), Epistemology: An anthology (pp. 301-313). Malden, MA: Blackwell Publishing.

Kitcher, P. (1992). The naturalists return. The Philosophical Review, 101(1), 53-114.

Laudan, L. (1990). Normative naturalism. Philosophy of Science, 57, 44-59.

Lipton, P. (1991/2004). Inference to the best explanation. New York: Routledge.

Maffie, J. (1990). Recent work on naturalized epistemology. American Philosophical Quarterly, 27, 281-293.

Mayo, D. G. (1996). Error and the growth of experimental knowledge. Chicago: The University of Chicago Press.

Messick, S. (1989). Validity. In R. L. Linn (Ed.), Educational measurement (pp. 13-103). New York: American Council on Education/Macmillan Publishing Company.

Newton, I. (1687/1848). Mathematical principles of natural philosophy. (Trans. by A. Motte, New York: Daniel Adee).

Peirce, C. S. (1877a/2006). Some consequences of four incapacities. In S. Haack (Ed.), Pragmatism, old \& new. Selected writings (pp. 69-105). New York: Prometheus Books.

Peirce, C. S. (1877b/2006). The fixation of belief. In S. Haack (Ed.), Pragmatism, old \& new. Selected writings (pp. 107-126). New York: Prometheus Books.

Peirce, C. S. (1878/2006). How to make our ideas clear. In S. Haack (Ed.), Pragmatism, old \& new. Selected writings (pp. 127-150). New York: Prometheus Books.

Peirce, C. S. (1902-1907/2006). Pragmatism and pragmaticism. In S. Haack (Ed.), Pragmatism, old \& new. Selected writings (pp. 151-167). New York: Prometheus Books. 
Quine, W. V. O. (1990/2003). Pursuit of Truth. Cambridge, MA: Harvard University Press.

Quine, W. V. O \& Ullian, J. S. (1970/1978). The web of belief. New York: McGraw-Hill Inc.

Rescher, N. (1977). Methodological pragmatism. A systems-theoretic approach to the theory of knowledge. New York: New York University Press.

Steinle, F. (1997). Entering new fields: Exploratory uses of experimentation. Philosophy of Science, 64(Supplement), s65-s74.

Suppes, P. (1985). Explaining the unpredictable. Erkenntnis, 22, 187-195.

Suppes, P. (1998). Pragmatism in physics. In P. Weingartner, G. Schurz, \& G. Dorn (Eds.), The role of pragmatics in contemporary philosophy (pp. 236-253). Vienna: Hölder-Pichler-Tempsky.

Vailati, G. (1907). The attack on distinctions. The Journal of Philosophy and Scientific Methods, 4, 701-709.

Vailati, G., \& Calderoni, M. (1909/2010). The origins and the fundamental idea of pragmatism. In C. Arrighi, P. Cantú, M. de Zan, \& P. Suppes (Eds.), Logic and pragmatism: Selected essays by Giovanni Vailati (Chap. 18). Stanford: CSLI Publications. 